Research Article

\title{
The Method of Determining Excavation Damaged Zone by Acoustic Test and the Application in Engineering Cases
}

\author{
Qian-Cheng Sun $\mathbb{D}^{1,},{ }^{1,2}$ Hao-Sen Guo $\mathbb{D}^{1,3},{ }^{1,3}$ Zhi-Hua Xu $\mathbb{D}^{1},{ }^{1}$ Yue Liu, ${ }^{1}$ and Xiao Xu ${ }^{1}$ \\ ${ }^{1}$ Key Laboratory of Geological Hazards on Three Gorges Reservoir Area (China Three Gorges University), Ministry of Education, \\ Yichang 443002, China \\ ${ }^{2}$ State Key Laboratory of Geomechanics and Geotechnical Engineering, Institute of Rock and Soil Mechanics, \\ Chinese Academy of Sciences, Wuhan, Hubei 430071, China \\ ${ }^{3}$ East China Jiaotong University, Nanchang 330000, China
}

Correspondence should be addressed to Hao-Sen Guo; 3048@ecjtu.edu.cn and Zhi-Hua Xu; zhihuabest@163.com

Received 24 January 2021; Accepted 27 April 2021; Published 29 May 2021

Academic Editor: Robert Černý

Copyright (c) 2021 Qian-Cheng Sun et al. This is an open access article distributed under the Creative Commons Attribution License, which permits unrestricted use, distribution, and reproduction in any medium, provided the original work is properly cited.

\begin{abstract}
It is very important to accurately determine the depth of excavation damaged zone for underground engineering excavation and surrounding rock stability evaluation, and it can be measured by acoustic test, but there is no quantitative method for analysis of the results, and it relies heavily on the experience of engineers, which leads to the low reliability of the results and also limits the application of the acoustic method. According to substantial field test data and the feedback of surrounding rock support parameters, the boundary method is proposed to determine the depth of excavation damaged zone in surrounding rock based on the relation between the ultrasonic velocity of measured point and the background wave velocity of rock mass. When the method is applied to the columnar jointed rock mass of Baihetan and the deep-buried hard rock of Jinping, the excavation damaged zone was well judged. The results in the Baihetan project show that the proposed method of determining excavation damage zone by the acoustic test can well demonstrate the anisotropy characteristics of the columnar jointed rock mass, and the damage evolution characteristics of jointed rock mass at the same position can also be obtained accurately. Moreover, the method also can accurately reveal the damage evolution process of the deep-buried hard rock under the condition of high ground stress, which proved the applicability of this method in jointed or nonjointed rock masses.
\end{abstract}

\section{Introduction}

With the intensification of energy utilization activities such as mining, geothermal development, and hydropower station construction, the stability of rock engineering is a common challenge faced by engineers and researchers. As early as the 1970s, foreign scholars as Kelsall put forward the importance of excavation damaged zone (EDZ) in construction of underground caverns [1]. Scholars have also studied the relationship between the depth of excavation damaged zone and its influencing factors, such as the buried depth, the section shape of caverns, the excavation and blasting method, the initial stress state, the mechanical properties of the rock mass, and the supporting state of the surrounding rock [2-6]. The depth of
EDZ and damage degree of surrounding rock are the basis of support parameter design and can play an early warning role in engineering disasters such as rock burst and spalling [7, 8]. Therefore, it is very important to accurately determine the depth of EDZ for underground engineering excavation and surrounding rock stability evaluation.

Although many scholars have obtained the theoretical calculation formula of excavation damaged zone depth according to the results of field test and indoor test, it has great limitations due to the influence of complex engineering factors in the application $[9,10]$. The field measured EDZ depth does not make any theoretical assumptions, and the test results can be more widely accepted. Generally, GPR method [11], seismic wave, multipoint displacement meter [12], and microseism and 
acoustic emission [13] are used to detect the depth of fracture zone in surrounding rock. However, these methods are complicated, costly, and difficult to conduct.

Generally, the excavation damaged zone consists of two parts. The observed interconnected macrofractures are referred to as the highly damaged zone, and the minor damaged zone is partially connected to isolated damage and is even invisible [14]. It is essential, for construction safety, to determine the depth of excavation damaged zone in rock masses around a tunnel. As a new testing method, drilling test technologies, including acoustic testing, digital borehole televiewers, are now widely used in field testing. During such tests, a borehole in local zones of rock masses is used to deduce changes in the internal properties of rock masses by analysing the test indexes of internal rock masses far from the free face. For example, by applying panoramic digital borehole televiewers, Li et al. [15] investigated the evolution of the EDZ in rock masses in deeply buried tunnels at the Jinping II Hydropower Station (Sichuan Province, China) during construction using tunnel boring machines (TBMs). On this basis, the changing characteristics of new cracks, primary fractures, and lithology during the excavation and support process of surrounding rocks were revealed. Moreover, by using testing technologies including acoustic wave technology over holes and sliding micrometers, the deformation conditions and rockburst risk, when excavating deeply buried parallel cavities in Jinping II Hydropower Station, were explored. Moreover, the formation and evolution mechanism of rockbursts were also discussed [16]. By applying acoustic testing technology, Martino and Chandler [17] evaluated the scope of EDZ in rocks surrounding deeply buried underground cavities. Guo et al. [18] explored the fracturing and evolutionary characteristics of EDZ in rocks surrounding Jinping's underground laboratory under the effect of excavation by employing DBT. By utilising the borehole testing method, a new understanding of the changes to the interior of rock masses during engineering activities can be obtained. Scholars have made a lot of meaningful exploration on the EDZ depth test by using acoustic testing method, but the current research results do not provide a clear judgment method based on the results of acoustic test. When the acoustic test is used in the field to determine the depth of excavation damage zone, it almost depends on the experience judgment of engineers, which leads to the low reliability of the results.

In order to increase the operability of the acoustic testing method in the field and improve the reliability of the EDZ test results, the boundary method, based on a large number of field measured data and the feedback of surrounding rock support parameters, is proposed to determine the depth of EDZ in surrounding rock, and the applicability of the proposed method is verified by comparing with the digital borehole televiewers test results.

\section{Method of Determining the Depth of EDZ by Acoustic Testing}

2.1. Introduction to Acoustic Testing. Acoustic testing is to excite the ultrasonic wave to propagate in the rock mass medium, and the propagation speed of the wave depends on the integrity of the rock mass. The wave velocity of intact rock mass is generally high, but it decreases relatively in the loose zone where the stress drops and the fracture expands. Therefore, there is an obvious change of wave velocity in rock mass with different damage degree. In highly damaged zone, there are visible cracks in the rock mass, which can be obtained by borehole television test. In minor damaged zones, although there are no visible fissures, the propagation of sonic wave velocity in this area still drops significantly compared with that of the original rock mass. Moreover, there is obvious uncertainty in the excavation disturbed zone, part of which becomes the original rock zone as the elastic deformation recovers, while the other part of rock mass produces damage during stress dissipation (a crest in the curve due to stress adjustment) and becomes part of the excavation damaged zone (minor or highly damaged zone). The curve of wave velocity at different lengths of drilling from the surface of surrounding rock can be obtained by using the propagation characteristics of ultrasonic wave, and then the EDZ depth of surrounding rock can be inferred according to the variation curve ( $V$ - $L$ curve) and relevant geological data (Figure 1).

The principle of acoustic testing is that the signal of transmitting transducer propagates in rock mass, and the time difference between two receiving transducers is used to estimate the propagation velocity of ultrasonic wave in rock mass. At present, the commonly used acoustic testing methods are single borehole acoustic test and cross hole acoustic test. The single borehole acoustic test method refers to measuring of the wave velocity of surrounding rock in a borehole by moving the transducers synchronously and sequentially. Most of the single hole acoustic testing equipment is a double-band acoustic transducer, which mainly consists of one transmitting transducer and two receiving transducers, as shown in Figure 2(a). The cross hole acoustic test method means that the receiving and transmitting transducers are respectively arranged in two measuring holes, and the receiving and transmitting transducers have the same initial depth and move synchronously with the same spacing to measure the wave velocity of rock strata or surrounding rock between the two holes, as shown in Figure 2(b).

For the single hole acoustic test method, the transmitter can be placed near or far away from the orifice according to the test environment. When testing the EDZ depth of surrounding rock, it is suggested that the transducer close to the orifice can be set as the receiving transducer. The measured wave velocity is the average wave velocity of rock mass between two receiving transducers. When drawing the $V$ - $L$ curve, the position of the wave velocity is the drilling length corresponding to the middle position of the two transducers. The distance between measuring points depends entirely on the moving distance of the testing equipment. Table 1 demonstrates four typical $V$ - $L$ curves according to the results of practical engineering test.

The initial wave velocity of type (a) is low and gradually increases with the borehole length and then tends to be stable, which indicates that the rock mass near the orifice causes plastic failure. The damage degree decreases with the increase of borehole length, and the integrity of the original 
rock section is good. The characteristics of type (b) are that the wave velocity near the borehole opening is relatively low. With the increase of length, the wave velocity at a certain position will even exceed that of the original rock section then decrease and then tend to be stable. In this kind of rock mass, the fracture is serious at the borehole position, and there is local stress concentration. The stress is relatively balanced with the increase of borehole length and the wave velocity is stable in the undisturbed original rock section. The characteristics of type (c) are that with the increase of borehole depth, multiple wave peaks appear on the curve, and the rock mass in this region is in the stress adjustment stage. After the adjustment, the rock mass is fractured, leading to a decrease in wave velocity. The wave velocity at local position, where the stress has not dissipated well, is still relatively high, and the rock mass in the undisturbed area gradually tends to be stable with the increase of length. The wave velocity of type (d) curve basically does not change with the change of borehole length, which indicates that the rock mass falls off directly after cracking, and there is no obvious damage area in the surrounding rock, and it can be considered that the surrounding rock in the test area has no plastic failure, and this type of curve is very rare in practical engineering.

\subsection{Drilling Layout and Monitoring Frequency. The most} intuitive way to determine the damage area by in situ testing is to conduct the test in predrilled hole before the tunnel excavation. The borehole should be arranged in the corresponding position where excavation damage is likely to occur. A large number of engineering practices and studies show that most of the cavity failure occurs at a small angle or approximately parallel to the direction of the maximum principal stress. For large deep caverns, with the occurrence of new cracks or original cracks opening in the excavation of caverns, the layout of boreholes should also be adjusted according to the excavation of caverns.

The layout of boreholes for acoustic testing needs to take equipment requirements into account. The outside diameter of the acoustic transducer is small, and the test process needs to ensure sufficient coupling between the probe and the rock mass, so the aperture of the test hole should not be too large. A test borehole diameter that is too small will affect the continuous testing process of the probe in the borehole and further affect the accurate acquisition of test data. Generally, the test borehole diameter should not be less than $60 \mathrm{~mm}$. The borehole shall be kept within the range of $1 \sim 5^{\circ}$ downward inclinations for manual operation, and the borehole axis shall be perpendicular to the section of the test sidewall. On the other hand, when using the cross hole acoustic test method, the two holes should have good parallelism. The test hole spacing should be determined according to the resolution of the instrument and the excitation energy and ensure that the ultrasonic signal can be well received, and the hole inclination measurement and hole spacing correction should be carried out before the test.

All kinds of auxiliary small tunnels (such as anchoring holes and drainage corridors) are often distributed around large caverns. Therefore, the layout of the test hole can choose preset hole or temporary hole. Preset hole means that the auxiliary tunnel can be used to set observation holes before the excavation of the test area (Figure 3 (1)), and the whole process of surrounding rock damage evolution before and after excavation can be observed. Temporary hole refers to drilling from the excavated area (Figure 3 (2)). In this way, the damage evolution process of surrounding rock after excavation and unloading can be tested.

The main purpose of EDZ testing is to monitor the extent of surrounding rock damage caused by excavation. When surrounding rock damage and stress unloading may occur in the observation hole, continuous observation should be made until the change process stops. Generally speaking, the stage of relatively severe development of surrounding rock cracking occurs during the redistribution of surrounding rock stress; that is, continuous excavation and unloading activities will lead to severe evolution of surrounding rock damage. Therefore, when construction activity occurs near the test hole, it should be observed closely. A large number of in situ test results showed that the damage area of deepburied hard rock is distributed in the scope of 1-time excavated chamber diameter, so the acoustic test shall be continuously observed during the construction of the double chamber diameter. For example, the chamber diameter of Jinping underground laboratory is $14 \mathrm{~m}$, and using drilling and blasting method to dig $3 \mathrm{~m}$ at a time, continuous observation is required during the construction within the excavation activity range of 5 times away from the preset hole, as shown in Figure 3(a).

2.3. Method of Determining the Depth of EDZ. According to a large number of field test data, combining with the results of support construction, the boundary method is proposed to determine the depth of EDZ in surrounding rock. It is a method to judge the critical point of surrounding rock EDZ depth based on the variation curve of rock wave velocity with drilling length ( $V-L$ curve), according to the relation between wave velocity of measured point and the background wave velocity of rock mass. To be specific, it is necessary to determine the background wave velocity of rock mass first. The background wave velocity of a single lithologic rock mass should be the average value of the stable wave velocity far away from the orifice, while for composite lithologic rock mass, it should be the average value of the stable wave velocity of the rock mass in same lithologic region as the excavation damage zone (Figure 3). If the background wave velocity cannot be determined by $V-L$ curve, the average value of undisturbed rock mass should be used instead, which can be found in the report of hydrogeological investigation before the excavation of the cavern. Then a parallel $X$ axis background wave velocity representative line, a reference line to determine the extent of the damage, is drawn on the V-P curve according to the wave velocity far away from the excavation affected area. Finally, when the wave velocity of three consecutive points (points $a, b$, and $c$ in Figure 4) near the orifice is smaller than the background wave velocity and these points show an upward trend, the 


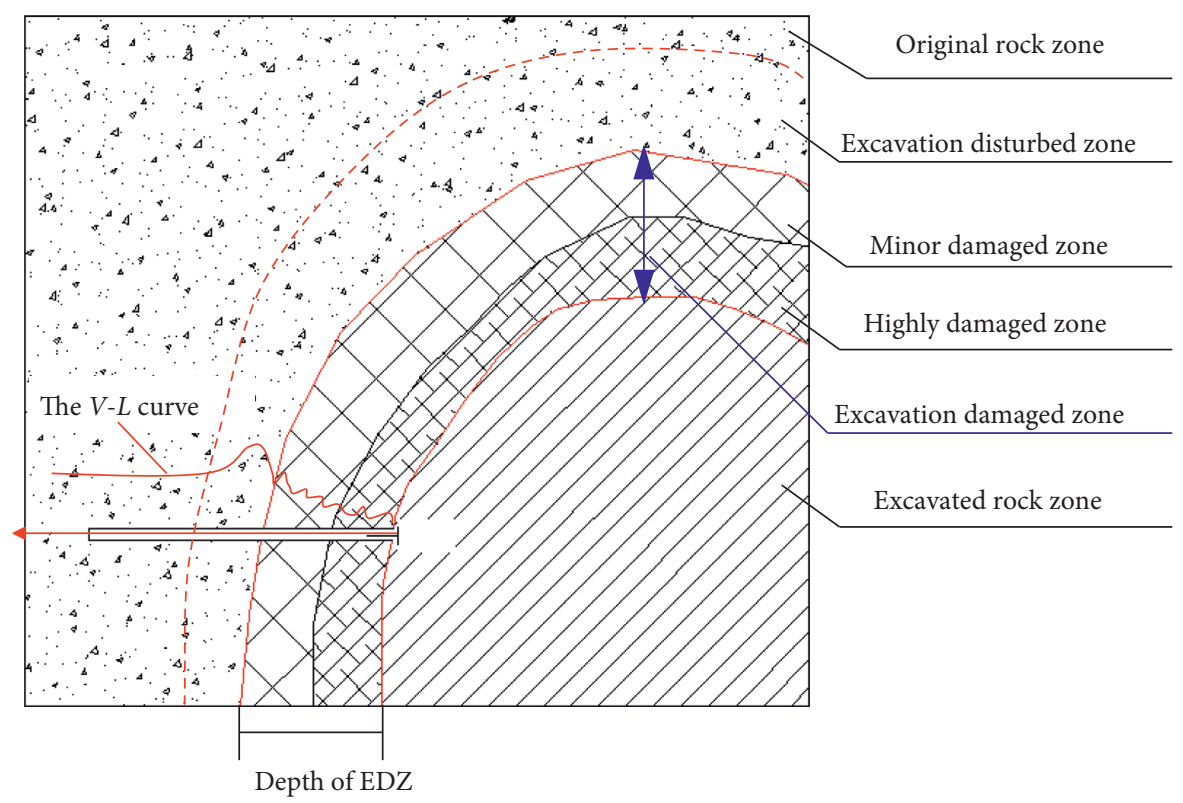

Figure 1: Principle of determining the depth of EDZ by acoustic testing.

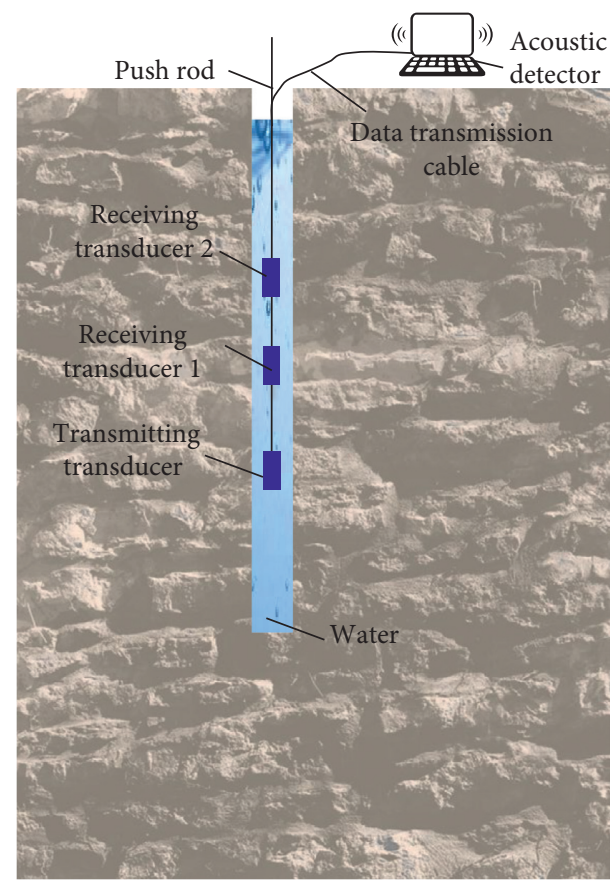

(a)

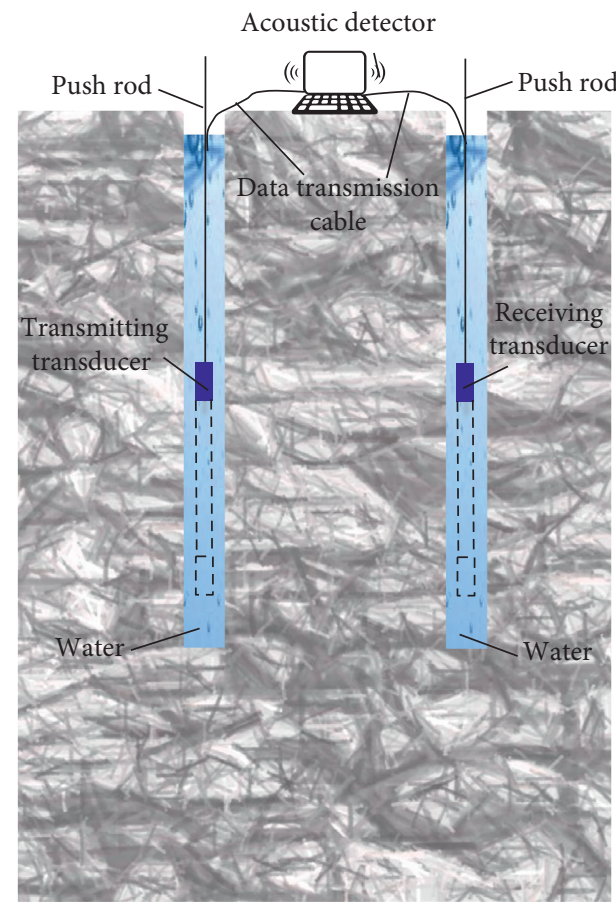

(b)

Figure 2: Principle of determining the depth of EDZ by acoustic testing. (a) Single hole acoustic test. (b) Cross hole acoustic test.

EDZ depth boundary is the closest measured point above the background wave velocity representative line (point $d$ in Figure 4).

It is worth noting that when the EDZ depth of surrounding rock is tested by a double receiver device, if the emission transducer is placed near the orifice, the acoustic wave of rock mass within the full length range of the device cannot be accurately tested. This is because the energy dissipation of acoustic signals released by the transmitter near the orifice is faster, the rock mass at the orifice is broken, and the acoustic signals entering the rock mass are even weaker. If the damage zone of the surrounding rock is small, the moving distance of the test equipment should be small, and generally no more than $10 \mathrm{~cm}$. If three points lower than the intrinsic wave velocity cannot be found by using the boundary method, the test position of all points 
TABLE 1: Typical $V$ - $L$ curves according to the results of practical engineering test.

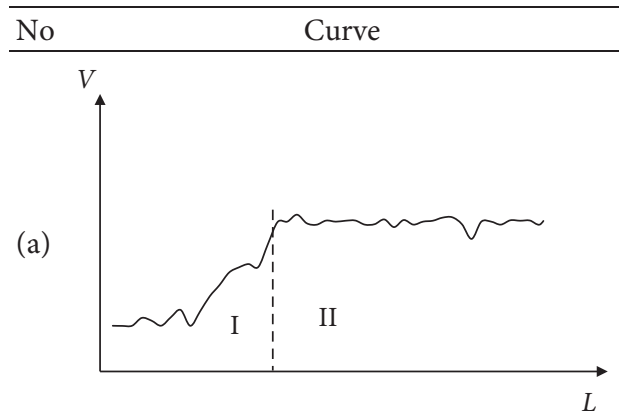

The wave velocity $V$ of rock mass near the orifice is very small. With the increase of hole length $L$, the wave velocity of rock mass increases rapidly, and then the growth rate slows down and gradually tends to be stable.

(b)

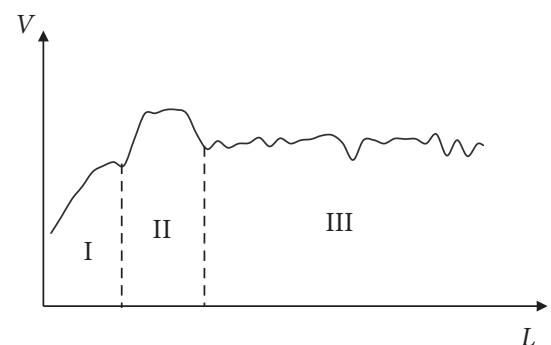

The wave velocity of rock mass can be divided into three distinct stages. Stage I is relatively low near the orifice. With the increase of hole length $L$, the wave velocity in stage II increases and then decreases within a certain range, and then the wave velocity gradually tends to be stable in stage III. (c)

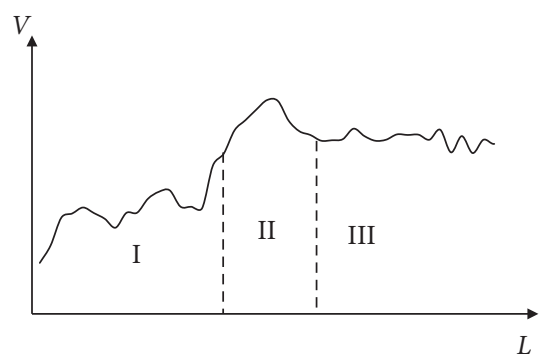

(d)

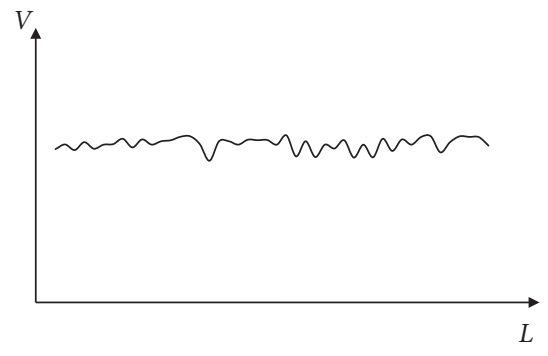

The wave velocity of rock mass also can be divided into three stages: stage I is near the orifice, and there are many wave peaks and troughs; the maximum wave peak appears in stage II, and stage III is that after the last wave peak far away from the orifice. The rock wave velocity gradually decreases and tends to be stable. near the orifice closest to the representative line of the background wave velocity can be determined as the damage depth boundary (Figure 5).

\section{Application in Engineering Cases}

\subsection{Application in Baihetan Engineering Project}

3.1.1. Introduction of the Engineering. Baihetan Hydropower Station is located on the border between Ningnan County in Sichuan Province and Qiaojia County in Yunnan Province on the lower reaches of the Jinsha River in China. According to the lithology of formations exposed during excavation, basalt of the Emeishan formation in the Permian system $(\mathrm{P} 2 \beta)$ is mainly found at the dam site, in which developed columnar jointed basalt appears in P2 332 and $\mathrm{P} 2 \beta 33$ layers.
The special structure of columnar jointed rock masses mainly appears as an abnormal development of joint fissures, in which not only intercolumnar joints making up the columnar body appear, but also intracolumnar vertical blind joint planes and intracolumnar horizontal and inclined joint planes are found. The statistical results pertaining to nearly 300 columnar joint planes within the elevation of $630 \sim 660 \mathrm{~m}$ of the dam foundation at the left bank showed that the proportions of columnar joints with triangular, quadrangular, pentagonal, and hexagonal sections are about $11.76 \%$, $29.41 \%, 32.35 \%$, and $26.47 \%$, respectively. The average length of the sides of these polygons is about $13.6 \mathrm{~cm}$ in which the total number of polygons whose length of side is in the range of $10 \sim 20 \mathrm{~cm}$ accounted for more than $80 \%$ overall. Columnar jointed basalts are intensively developed and the columnar joints are cut by a quantity of low-dip structural 


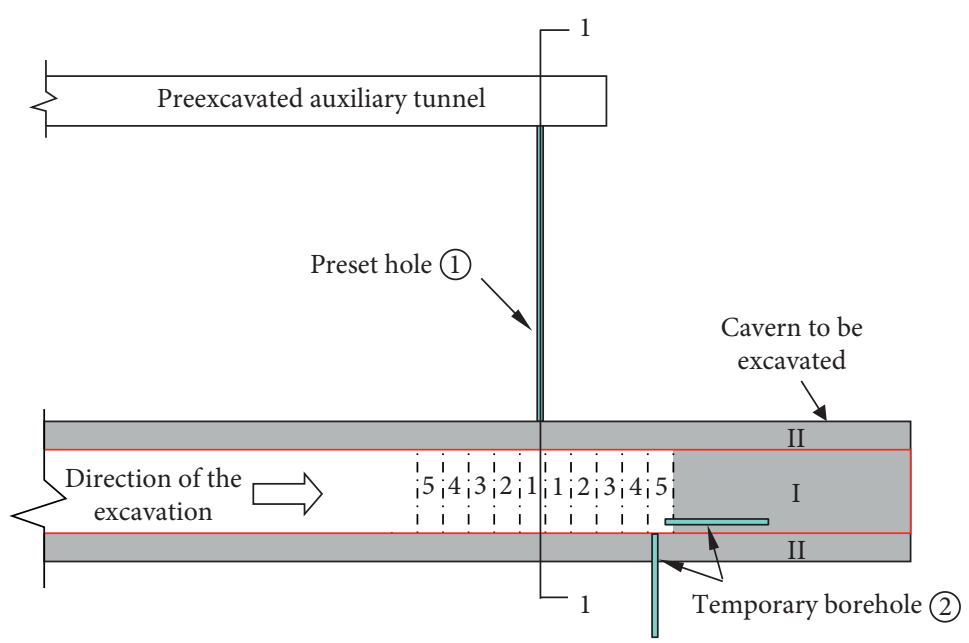

(a)

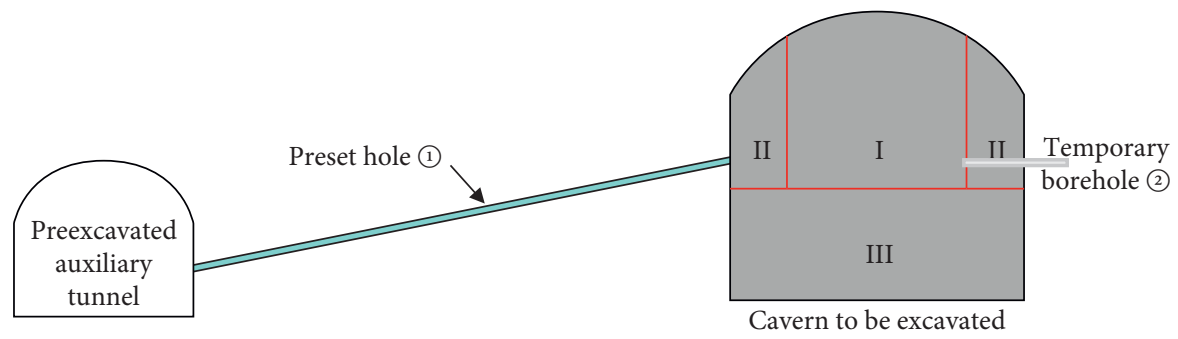

(b)

Figure 3: Layout of the test hole for acoustic testing. (a) Plane view and (b) section view of 1-1.

planes and dislocation zones. As a result, except for some zones influenced by tectonics, the inclinations of axes of columnar jointed basalts are all between $60^{\circ}$ and $85^{\circ}$.

In the experimental cavern, there are three types of drilling holes with the same diameter in the side wall, which are $45^{\circ}$ updipping, $45^{\circ}$ horizontal, and $45^{\circ}$ downward as shown in Figure 6.

3.1.2. Excavation Damaged Zone of the Jointed Rock Mass from Different Boreholes. In the columnar jointed rock mass cavern, the highly damaged zones in rock mass measured by boreholes with different angles on the left wall are almost the same, while the excavation damaged zones determined by acoustic wave tests vary from each other (Figure 7), and their evolution rules are also different, which is mainly caused by the different relative positions of the primary jointed surface and the borehole. The greater the angle of intersection between the borehole and joint surface, the greater the amplitude of change of acoustic wave propagation path, and the more the number of joints across the borehole per unit length, the more energy loss of acoustic wave in the propagation process. The microfractures in the column expand or break through after the formation of the hole, so that when the boreholes from different angles cross the columnar jointed rock mass, the number of fissures in the drilling wall per unit length is obviously different. This is an important reason that the wave velocities of the original rock mass differ greatly from each other by drilling tests from different angles.

E4 refers to the boreholes at the left spandrel of the diversion tunnel on the left bank of Baihetan Hydropower Station. The evolution of HDZ and EDZ in borehole E4 during different excavation stages was monitored in real time. According to the initial data from boreholes, there were six primary through-going fractures and a block dropping event in the borehole, with the length of HDZ and EDZ being $1.9 \mathrm{~m}$ and $2.4 \mathrm{~m}$. After the working face passed $4 \mathrm{~m}$ from the measurement point, new fractures appeared at distances of $0.7 \mathrm{~m}$ and $2.0 \mathrm{~m}$ and a block dropped at $0.9 \mathrm{~m}$ along the borehole. Moreover, the fracture at $1.9 \mathrm{~m}$ extended from $25.1 \mathrm{~mm}$ to $86.6 \mathrm{~mm}$ in width. When the working face was $9 \mathrm{~m}$ from the measurement borehole, new fractures appeared at $0.6 \mathrm{~m}$ and $1.6 \mathrm{~m}$ and a block dropped at $1.1 \mathrm{~m}$ within the borehole. Moreover, the fracture at $1.9 \mathrm{~m}$ further extended from $86.6 \mathrm{~mm}$ to $131.2 \mathrm{~mm}$ in width. The fracture at $2.0 \mathrm{~m}$ was connected with other fractures and the length of the fracture zone increased to $2.1 \mathrm{~m}$, and the length of excavation damaged zone increased to $2.8 \mathrm{~m}$ as well (Figure 8 ).

\subsection{Application in Jinping Deep Underground Laboratory}

3.2.1. Introduction of the Engineering. Jinping Deep Underground Laboratory (CJPL-II) is situated in the geomorphological slope between Sichuan Basin and Qinghai-Tibet 


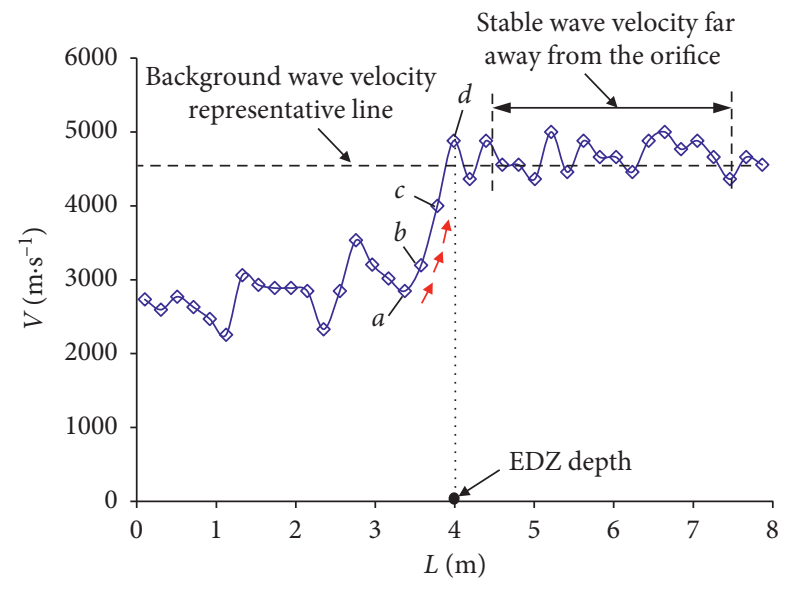

FIgURE 4: The proposed boundary method.

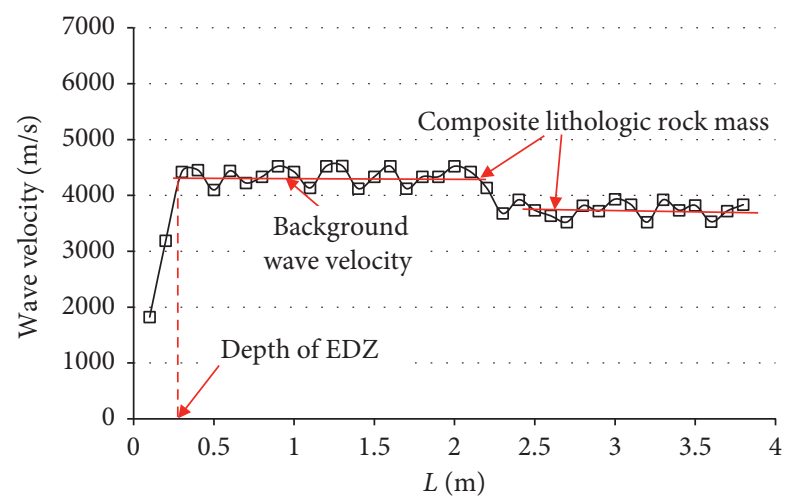

Figure 5: Boundary method used in composite lithologic rock mass.

Plateau. It is located in Jinping Mountain at the lower reaches of Yalong River and the junction of Muli, Yanyuan and Mianning counties, Sichuan, The cliff of Jinping Mountain stands precipitously, and the ridge is mostly in the shape of sharp edge, and the ridge on both sides of the main ridge is in the shape of comb, and the maximum relative height difference exceeds $3000 \mathrm{~m}$ (Figure 9).

Jinping Deep Underground Laboratory II phase (CJPLII) Rock Mechanics Underground Laboratory buried $2375 \mathrm{~m}$ belongs to the ultradeep underground laboratory. According to the functional design requirements of the second phase of Jinping Deep Underground Laboratory, combined with geological conditions, existing caves arrangement and construction conditions, the underground laboratory consists of four staggered traffic holes, each hole is $130 \mathrm{~m}$ long, with two test holes of $65 \mathrm{~m}$ in length, forming an overall pattern of 4 holes with 9 chambers, as shown in Figure 10. The axis direction of test holes is parallel to the auxiliary guide hole of Jinping, and the axis azimuth is $\mathrm{N} 58^{\circ} \mathrm{W}$, and the excavation process for $1 \# \sim 8 \#$ test hole, gate shaped with section of $14 \times 14 \mathrm{~m}$, can be divided into three steps, including upper middle drift excavation (Step I), upper expansion excavation (Step II), and bottom excavation (Step III). While the 9-1\# test hole is a $5 \mathrm{~m}$ circular chamber with full section excavation, the main supporting methods are bolt and shotcrete. The lithology of test grotto \#2, \#3, and \#4 in the engineering area changed significantly.

3.2.2. Excavation Damaged Zone of the Jointed Rock Mass from Different Boreholes. C-04 is a preset drill hole before the excavation of 6\# test grotto (Figure 11). The lithology is gray marble. The drill hole is shown in Figure 10. On April 1, 2015, the acoustic wave velocity of C-04 hole and the initial borehole camera data were measured before excavation. The original rock wave velocity of the gray marble was measured to be $5800 \mathrm{~km} / \mathrm{s}$, except that it decreased slightly in the region where the original fracture was located, and the wave velocity of the rock mass in the whole section was stable. The excavation of 6\# test grotto began in May 2015, and the damaged area gradually emerged and evolved during the excavation stage. On August 25, 2015, when the upper expansion excavation was $8 \mathrm{~m}$ away from the measuring hole, the borehole camera and acoustic test within $4 \mathrm{~m}$ of the surrounding rock were carried out in situ. The results of borehole photography showed that several new cracks have been added in the hole, and the original cracks have opened locally, forming a $2.1 \mathrm{~m}$ highly damaged zone. According to the "boundary method" proposed in this paper, the depth of excavation damaged zone by acoustic test was about $3.1 \mathrm{~m}$ (Figure 12). 


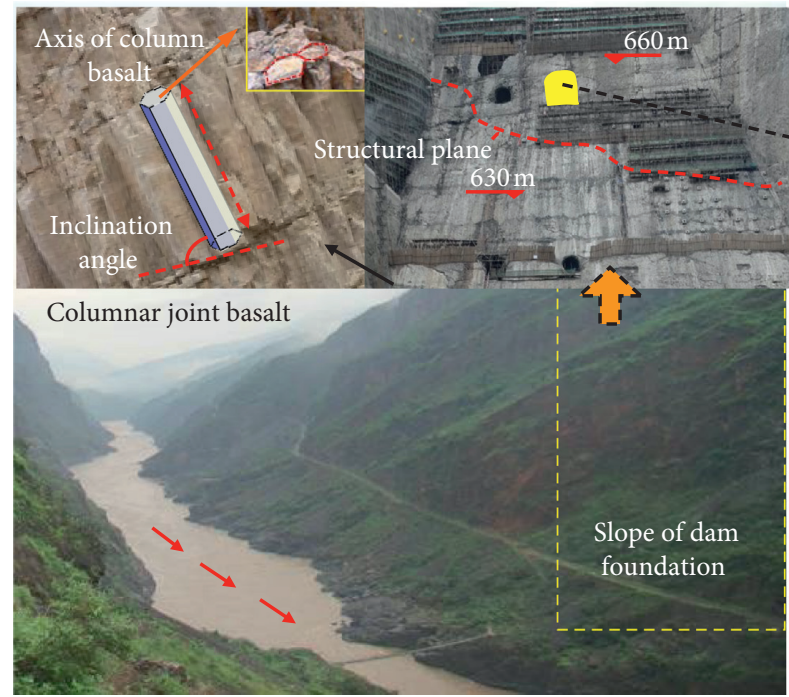

(a)

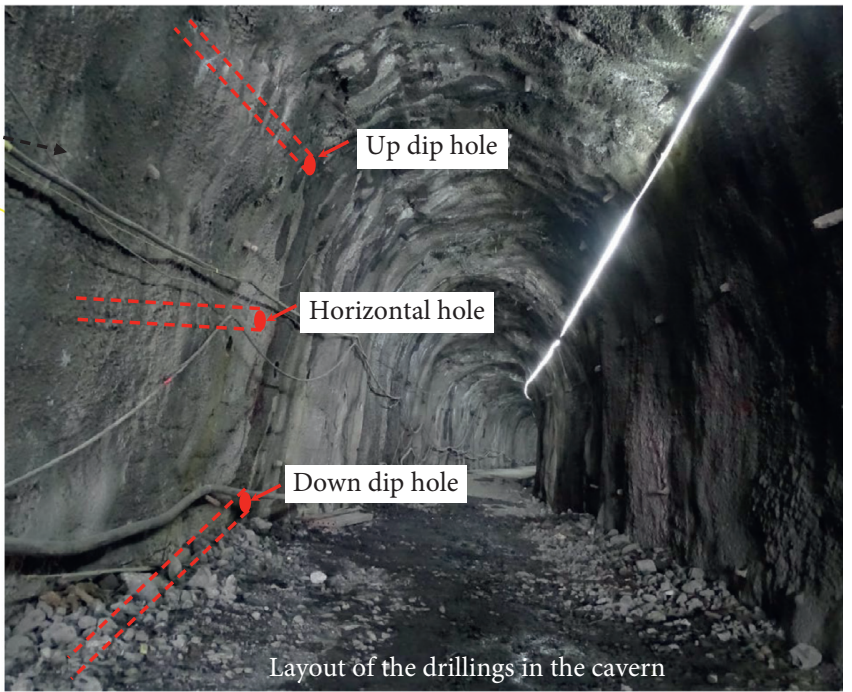

(b)

Figure 6: Columnar joint basalt on the slope of dam foundation in Baihetan.

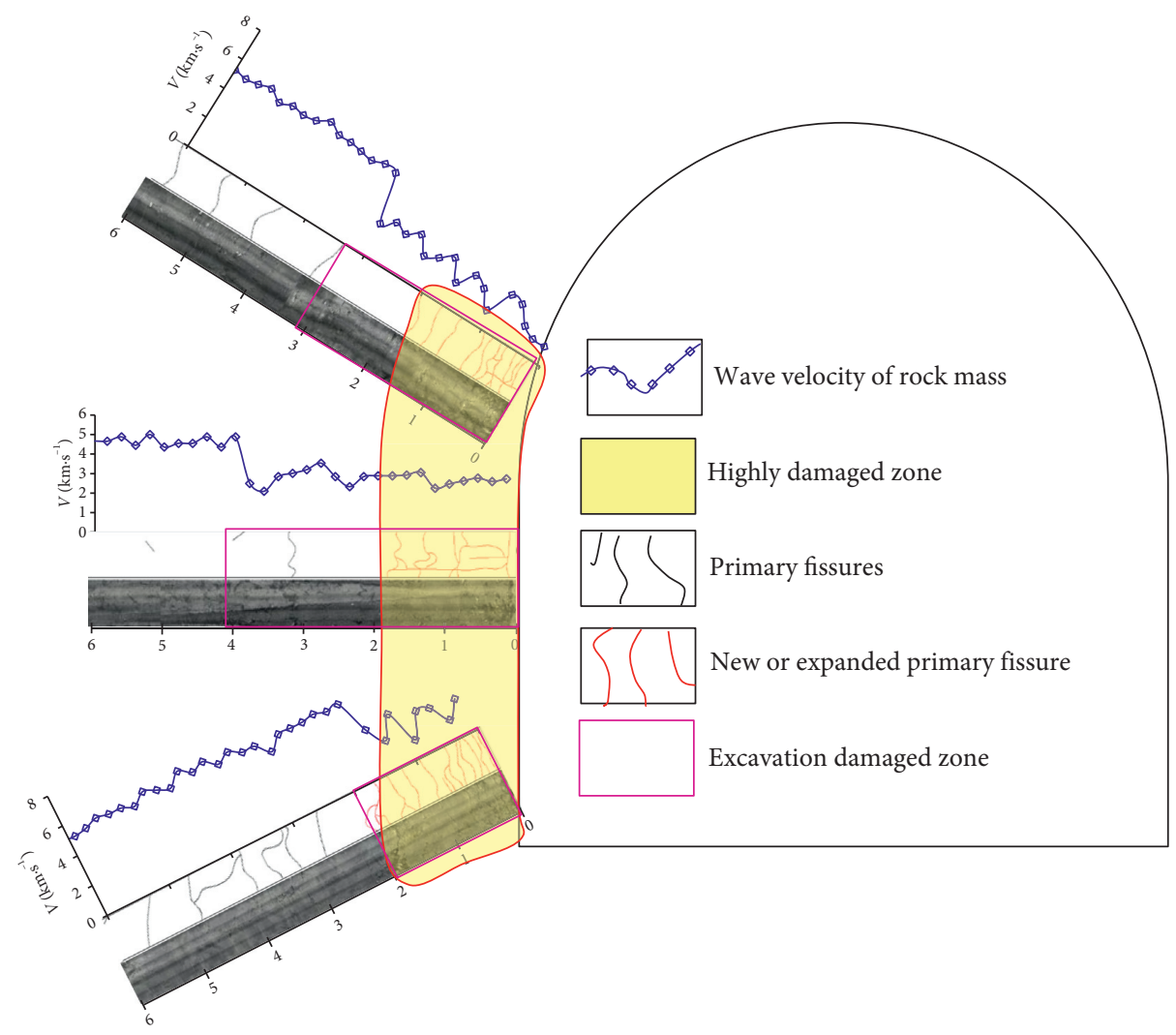

FIGURE 7: Test results of boreholes at different angles in jointed rock mass.

C-02 is a preset drill hole before the excavation of $2 \#$ test grotto. The lithology is black-streaked fine-grained marble. The drilling is shown in Figure 11. On April 1, 2015, the acoustic wave velocity of $\mathrm{C}-02$ and the initial borehole camera data were measured before excavation. The original rock wave velocity was $6000 \mathrm{~km} / \mathrm{s}$, which indicated that, compared with gray marble in C-04, the black-streaked fine- grained marble in C-02 has higher strength and better rock integrity. On September 18, 2015, when the bottom excavation was $4 \mathrm{~m}$ away from the measuring drilling, the borehole camera and acoustic test within $4 \mathrm{~m}$ of the surrounding rock were carried out in situ. The results of borehole photography showed that several new cracks have been added in the hole, and the original cracks have opened 


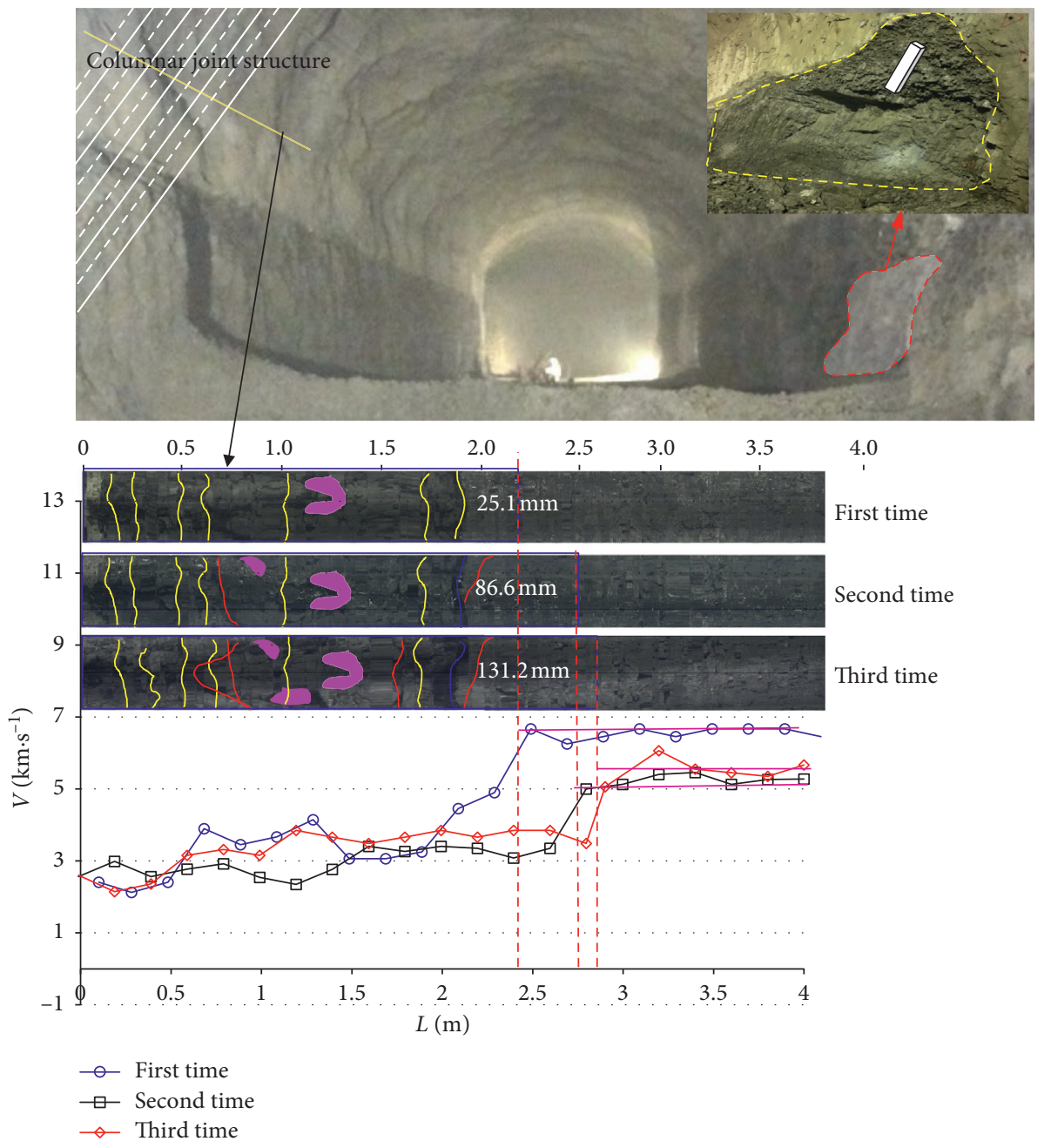

Figure 8: Test results of E4 in jointed rock mass.

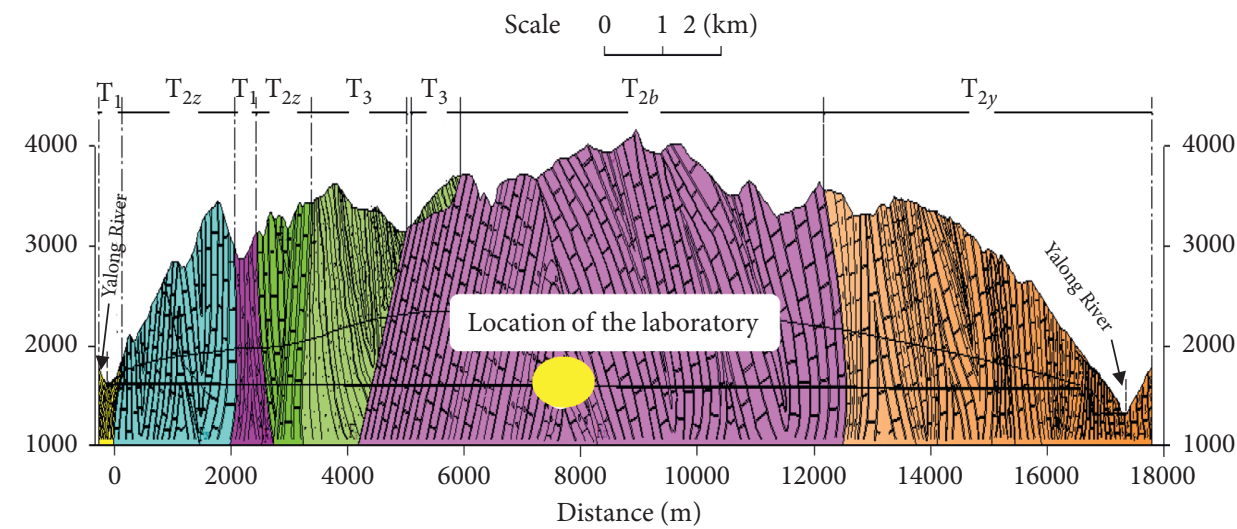

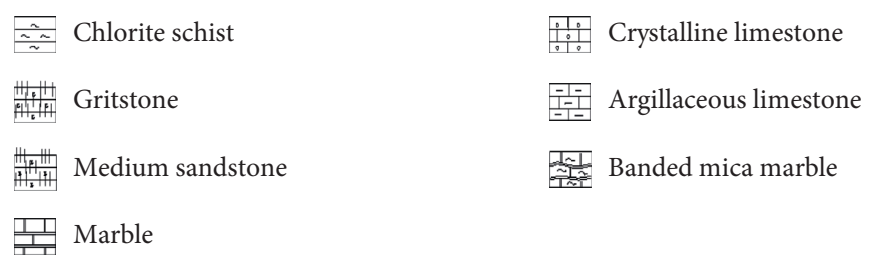

FIgURE 9: Location of Jinping deep underground laboratory. 


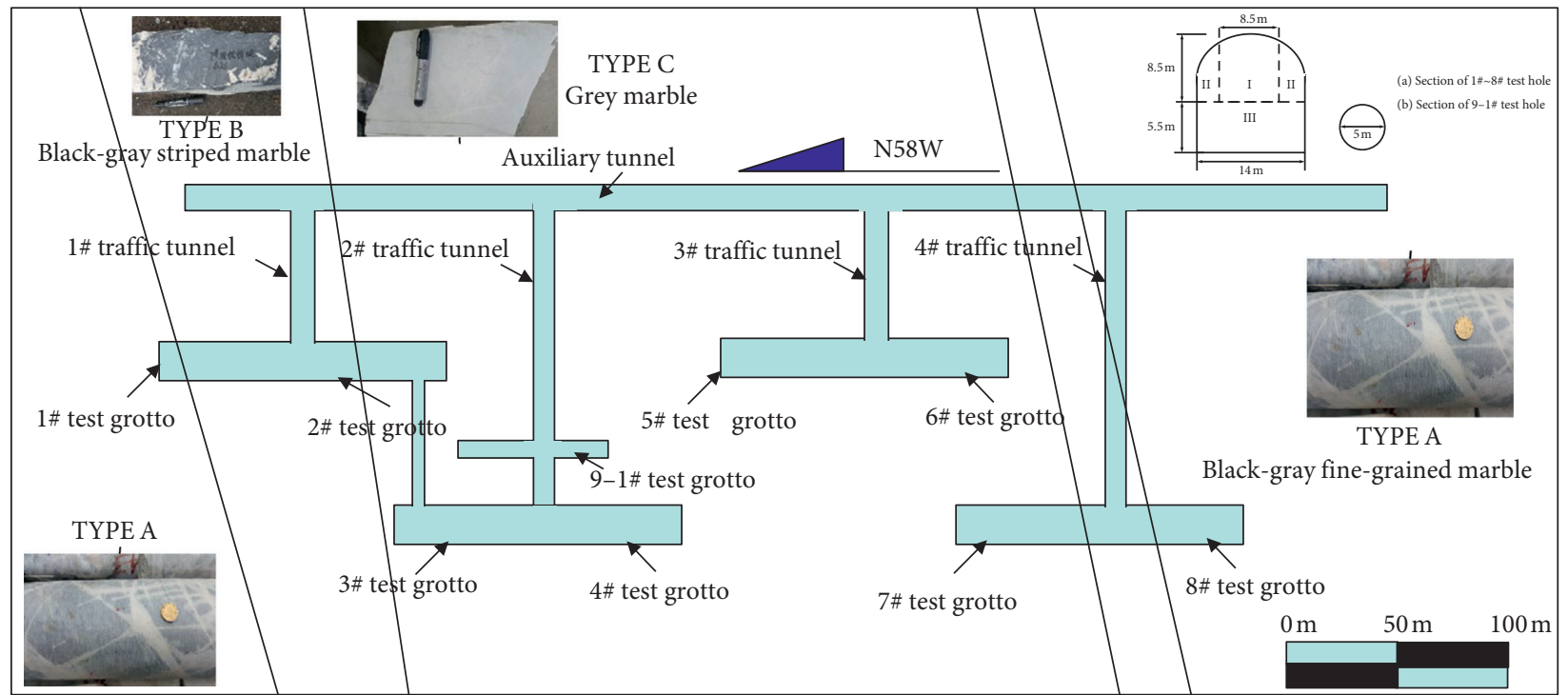

FiguRE 10: Layout of Jinping deep underground laboratory.

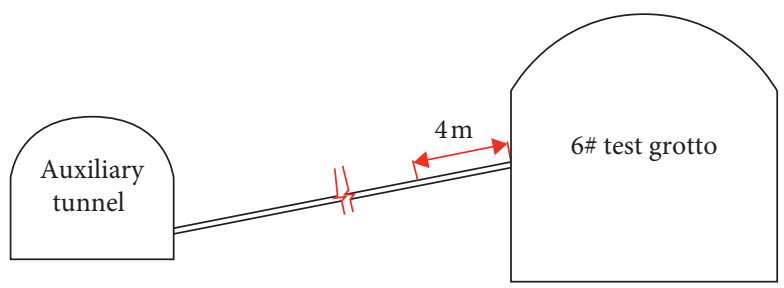

Setting of drilling C-04

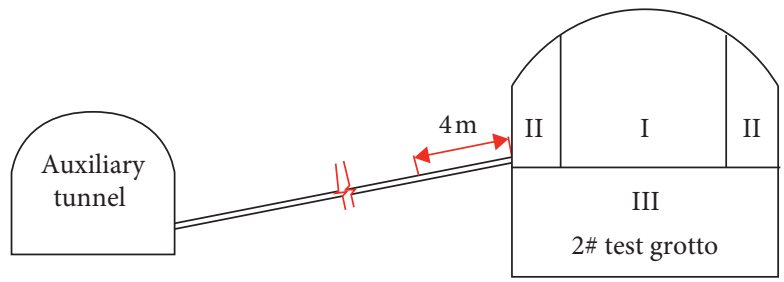

Setting of drilling C-02

Figure 11: Layout of C-02 and C-04.

locally, forming a $1.1 \mathrm{~m}$ highly damaged zone. According to the "boundary method" proposed in this paper, the depth of excavation damaged zone by acoustic test was about $1.6 \mathrm{~m}$, as shown in Figure 13.

\section{Discussion}

Because of its simple operation and high test accuracy, acoustic test is superior to other test methods, so it occupies the mainstream position of current test methods to determine the depth of EDZ in surrounding rock mass.

However, in practical engineering, the acoustic wave velocity of surrounding rock is not only affected by the damage of surrounding rock, but also by the inhomogeneity of lithology and fault structure, etc., so it would be more complex, which increases the difficulty in determining the EDZ depth of rock mass to some extent. In addition, the deformation and fracture of rock mass are generally the results of progressive damage degradation and continuous accumulation process from the initial microdefects to the final fracture failure, which is also the result of the continuous expansion and penetration of internal microdefects. Sometimes the proposed method is not applicable in zonal fractured rock masses (Figure 14). In zonal fractured rock masses, determining of EDZ depth requires combining testing purposes. For example, if it is used for surrounding rock bolting; the nature of the rock mass and the length of partition should be taken into consideration. 

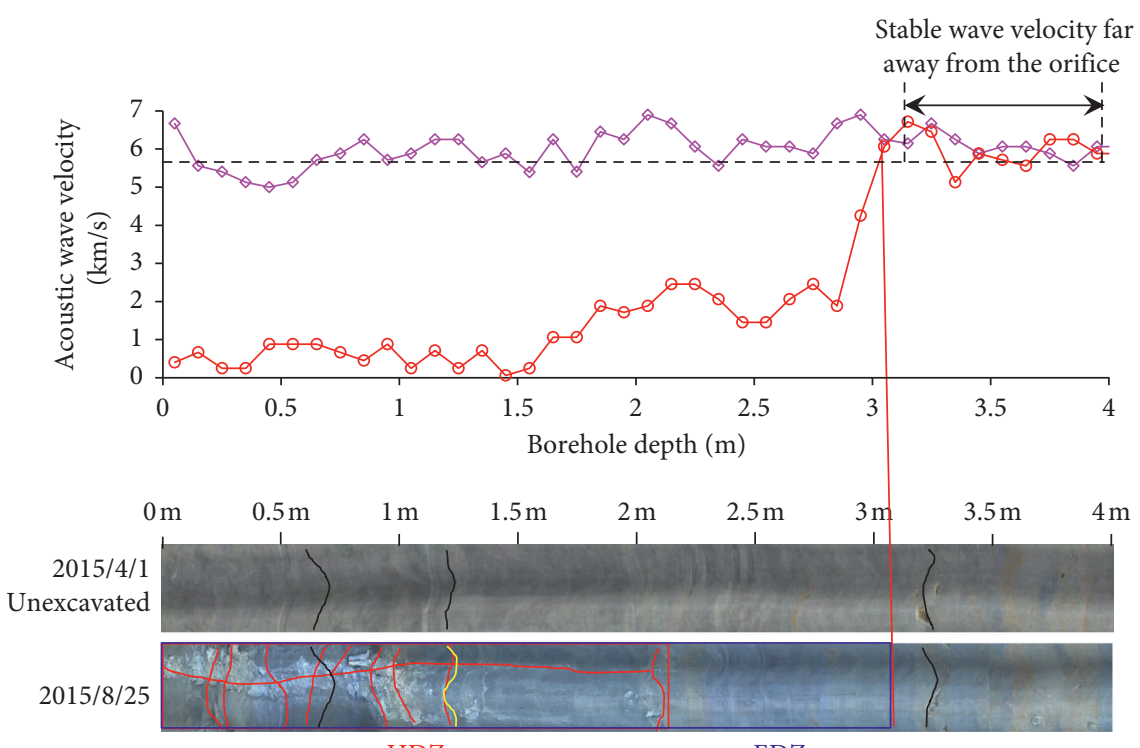

HDZ

EDZ

$\diamond-2015 / 4 / 1$

- 2015/8/25

Figure 12: Test results of C-04 in 6\# test grotto.
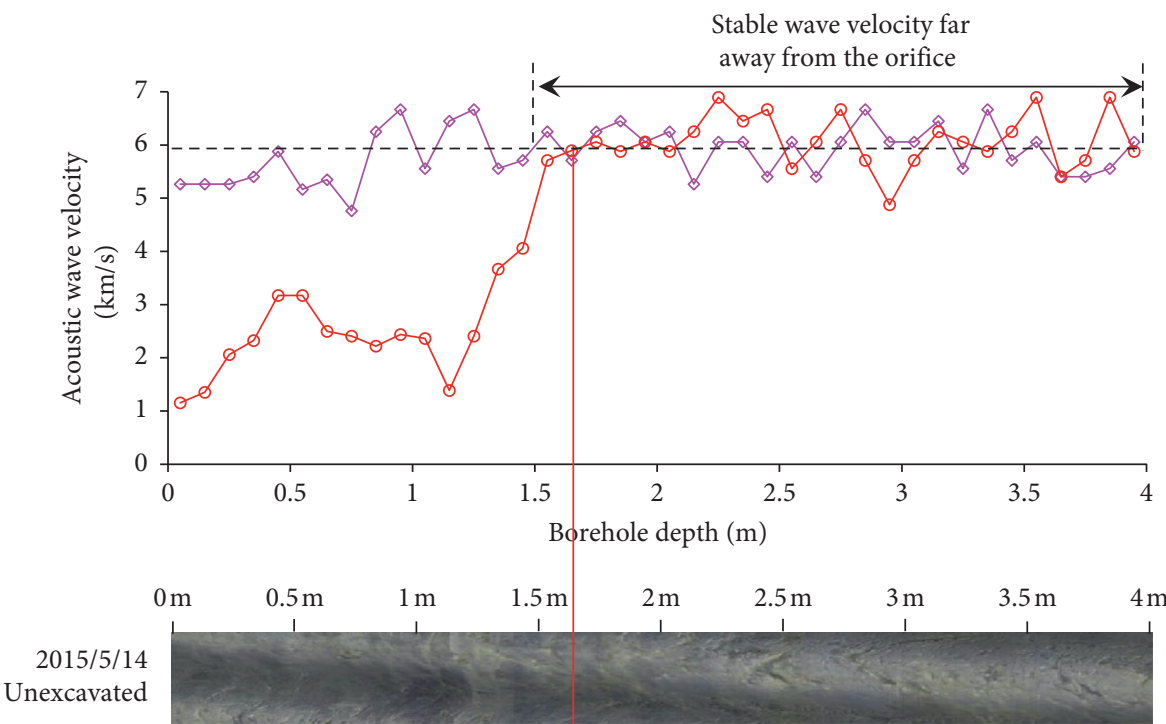

$2016 / 8 / 10$

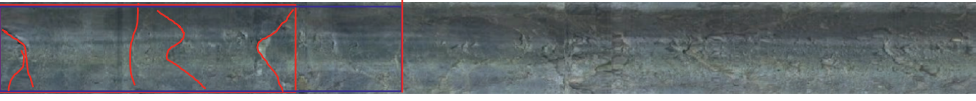

HDZ

EDZ

$\neg$ 2015/5/14

- $2016 / 8 / 10$

Figure 13: Test results of C-02 in 2\# test grotto. 


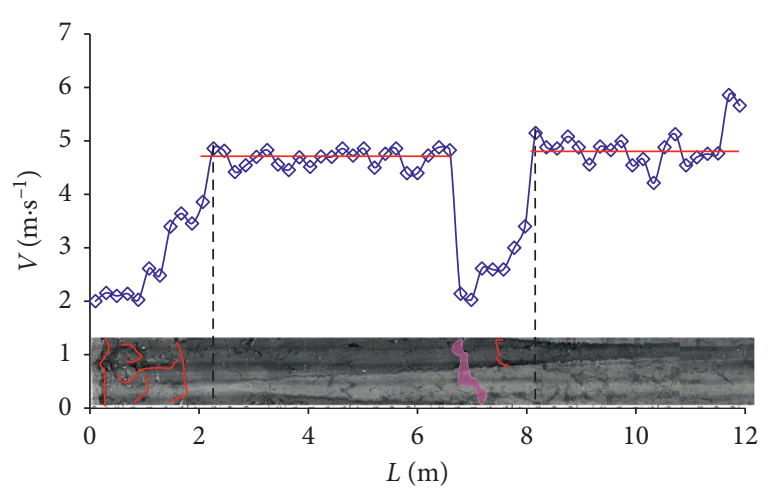

Figure 14: Acoustic test in zonal fractured rock masses.

\section{Conclusions}

The accurate determination of excavation damaged zone depth directly affects the reasonable selection of supporting parameters after excavation of surrounding rock. On the basis of previous studies, the commonly used acoustic testing method is demonstrated in this work, and the method of determining excavation damage zone by acoustic testing is proposed. The main conclusions drawn as follows.

(1) For jointed rock mass, the anisotropy is the main factor affecting the propagation law of acoustic wave. The depth of excavation damaged zone obtained by acoustic wave represents the damage degree of rock mass affected by excavation in this direction. The damage evolution of rock mass at the same position after excavation obtained by acoustic test is consistent with the fracture evolution of borehole television, but the acoustic wave test results can better reflect the influenced area under excavation.

(2) For deep-buried hard rock, the damage evolution characteristics of rock mass are obviously correlated with lithology. Although the background wave velocity of different hard rocks varies significantly, the depth of excavation damaged zone obtained by acoustic wave test can also reflect the differences in the evolution process.

(3) The proposed method is based on the basic law of rock damage evolution and the propagation characteristics of acoustic waves in rock media of different states. The acoustic wave testing method is simple and easy to operate, and the proposed method for analysing test results is highly operable and reliable in both preset and newly arranged drilling holes.

\section{Data Availability}

The data used to support the findings of this study are available from the corresponding author upon request.

\section{Conflicts of Interest}

The authors declare no conflicts of interest.

\section{Acknowledgments}

This research was funded by the National Natural Science Foundation of China (grant no. 51909136), the Open Research Fund of Key Laboratory of State Key Laboratory of Geomechanics and Geotechnical Engineering (grant no. Z018012), and the Open Research Fund of Key Laboratory of Geological Hazards on Three Gorges Reservoir Area (China Three Gorges University), Ministry of Education (grant no. 2020KDZ03). The authors gratefully acknowledge the support by Young Talents Development Plan of Hubei Province. The authors appreciate the value added through discussion of the work with Zhibin Yao and Professor Shaojun Li.

\section{References}

[1] P. C. Kelsall, J. B. Case, and C. R. Chabannes, "Evaluation of excavation-induced changes in rock permeability," International Journal of Rock Mechanics and Mining Sciences \& Geomechanics Abstracts, vol. 21, no. 3, pp. 123-135, 1984.

[2] R. Pusch and R. Stanfors, "The zone of disturbance around blasted tunnels at depth," International Journal of Rock Mechanics and Mining Sciences \& Geomechanics Abstracts, vol. 29, no. 5, pp. 447-456, 1992.

[3] T. Sato, T. Kikuchi, and K. Sugihara, "In-situ experiments on an excavation disturbed zone induced by mechanical excavation in Neogene sedimentary rock at Tono mine, central Japan," Engineering Geology, vol. 56, no. 1-2, pp. 97-108, 2000.

[4] X. Lai, F. H. Ren, Y. P. Wu, and M. F. Cai, "Comprehensive assessment on dynamic roof instability under fractured rock mass conditions in the excavation disturbed zone," International Journal of Minerals, Metallurgy and Materials, vol. 16, no. 1, pp. 12-18, 2009.

[5] A. T. Jakubick and T. Franz, "Vacuum testing of the permeability of the excavation damaged zone," Rock Mechanics and Rock Engineering, vol. 26, no. 2, pp. 165-182, 1993.

[6] Z. Hou, "Mechanical and hydraulic behavior of rock salt in the excavation disturbed zone around underground facilities," International Journal of Rock Mechanics and Mining Sciences, vol. 40, no. 5, pp. 725-738, 2003.

[7] G. L. Feng, X. T. Feng, B. R. Chen et al., "Characteristics of microseismicity during breakthrough in deep tunnels: case study of Jinping-II hydropower station in China," International Journal of Geomechanics, vol. 20, Article ID 04019163, 2020.

[8] G.-L. Feng, X.-T. Feng, B.-R. Chen, Y.-X. Xiao, and Z.-N. Zhao, "Effects of structural planes on the microseismicity associated with rockburst development processes in deep tunnels of the Jinping-II Hydropower Station, China," Tunnelling and Underground Space Technology, vol. 84, pp. 273-280, 2019.

[9] S. Kwon, C. S. Lee, S. J. Cho, S. W. Jeon, and W. J. Cho, “An investigation of the excavation damaged zone at the KAERI underground research tunnel," Tunnelling and Underground Space Technology, vol. 24, no. 1, pp. 1-13, 2009.

[10] I. Vazaios, N. Vlachopoulos, and M. S. Diederichs, "Assessing fracturing mechanisms and evolution of excavation damaged zone of tunnels in interlocked rock masses at high stresses using a finite-discrete element approach," Journal of Rock Mechanics and Geotechnical Engineering, vol. 11, no. 4, pp. 701-722, 2019.

[11] R. S. Read, "20 years of excavation response studies at AECL's underground research laboratory," International Journal of 
Rock Mechanics and Mining Sciences, vol. 41, no. 8, pp. 1251-1275, 2004.

[12] D. P. Jansen, S. R. Carlson, R. P. Young, and D. A. Hutchins, "Ultrasonic imaging and acoustic emission monitoring of thermally induced microcracks in Lac du Bonnet granite," Journal of Geophysical Research: Solid Earth, vol. 98, no. B12, pp. 22231-22243, 1993.

[13] S. R. Carlson and R. P. Young, "Acoustic emission and ultrasonic velocity study of excavation-induced microcrack damage at the underground research laboratory," International Journal of Rock Mechanics and Mining Sciences \& Geomechanics Abstracts, vol. 30, no. 7, pp. 901-907, 1993.

[14] M. A. Perras and M. S. Diederichs, "Predicting excavation damage zone depths in brittle rocks," Journal of Rock Mechanics and Geotechnical Engineering, vol. 8, no. 1, pp. 60-74, 2016.

[15] S. Li, X.-T. Feng, Z. Li, C. Zhang, and B. Chen, "Evolution of fractures in the excavation damaged zone of a deeply buried tunnel during TBM construction," International Journal of Rock Mechanics and Mining Sciences, vol. 55, pp. 125-138, 2012.

[16] S. Li, X.-T. Feng, Z. Li, B. Chen, C. Zhang, and H. Zhou, "In situ monitoring of rockburst nucleation and evolution in the deeply buried tunnels of Jinping II hydropower station," Engineering Geology, vol. 137-138, pp. 85-96, 2012.

[17] J. B. Martino and N. A. Chandler, "Excavation-induced damage studies at the underground research laboratory," International Journal of Rock Mechanics and Mining Sciences, vol. 41, no. 8, pp. 1413-1426, 2004.

[18] H.-S. Guo, X.-T. Feng, S.-J. Li, C.-X. Yang, and Z.-B. Yao, "Evaluation of the integrity of deep rock masses using results of digital borehole televiewers," Rock Mechanics and Rock Engineering, vol. 50, no. 6, pp. 1371-1382, 2017. 